\title{
Energy-efficient motor systems in the industrial and in the services sectors in the European Union: characterisation, potentials, barriers and policies
}

\author{
Aníbal T. de Almeida ${ }^{\mathrm{a}, *}$, Paula Fonseca ${ }^{\mathrm{a}}$, Paolo Bertoldi ${ }^{\mathrm{b}}$ \\ ${ }^{a}$ ISR-Dep. Electrical Engineering and Computers, University of Coimbra, Coimbra, Portugal \\ ${ }^{\mathrm{b}}$ Directorate General of Energy and Transport, European Commission, Brussels, Belgium
}

Received 14 January 2002

\begin{abstract}
This paper shows how electricity is used by electric motors in both the industrial and the services' sectors in the European Union, as well as the potential electricity savings by the year 2015 with the application of Energy-Efficient Motors and Variable Speed Drives. Additionally, the main barriers identified in the field characterization study and the measures to overcome those barriers are presented.
\end{abstract}

(C) 2003 Elsevier Science Ltd. All rights reserved.

\section{Introduction}

Electric motors are by far the most important electric load, and therefore should be one key priority in large-scale market transformation and Demand Side Management (DSM) programs designed to achieve cost-effective electricity savings.

Based on a recent field characterization project supported by the European Union (EU) involving six countries (Denmark, France, Germany, Italy, Portugal and the UK), this paper characterizes the motor electricity consumption both in the industrial and the services sector in the European Union countries, and summarizes the estimated savings potential of the application of EnergyEfficient Motors (EEMs) and Variable Speed Drives (VSDs) by the year 2015. Most of the electricity used in industrialized countries is consumed in electric motor applications. Motor systems are responsible for about 69 and $38 \%$ of the electricity consumed in the industrial and in the services sectors in the European Union (EU), respectively, representing about 575 and $186 \mathrm{TWh}$

\footnotetext{
* Corresponding author. Tel.: +351-239-796218; fax: +351-239-406672.

E-mail address: adealmeida@isr.uc.pt (A.T. de Almeida).
} 


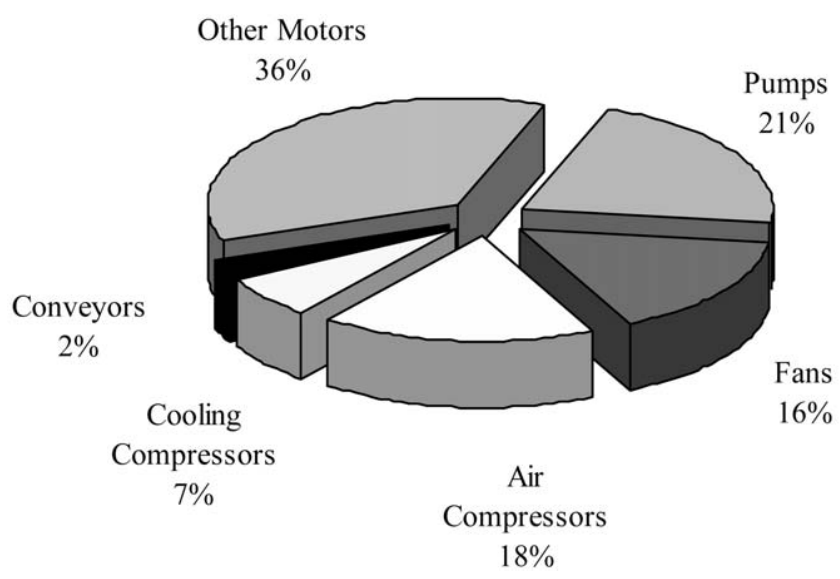

Fig. 1. Disaggregation of motor electricity consumption by end-use in the Industrial sector. Note: Other motors include a large variety of loads mainly associated with materials processing (mills, grinders, laminators, extruders, mixers, agitators, centrifugators, etc.) and materials handling (conveyors, lifts, hoists, packaging, etc.).

per year [1]. Pumps, fans and compressors are by far the most important loads in industry and in the services sectors, accounting for 62\% (Fig. 1) and $82 \%$ (Fig. 2) of the total motor electricity consumption respectively. This high share of controllable loads is particularly relevant when estimating the potential electricity savings with the application of VSDs. In many centrifugal pumps, fans and compressor applications, the mechanical power grows roughly with the cube of the fluid flow. So, small reductions in flow can yield significant energy savings. For instance, to move $80 \%$ of the nominal flow only half of the power is required. Centrifugal loads are therefore excellent candidates for motor speed control, instead of using inefficient fluid control devices such as valves, throttles and dampers.

This paper also presents an overview of the main barriers for the large-scale application of energy-efficient motor systems that have been identified in the field characterization, as well as strategies to overcome those barriers and promote energy-efficient motor systems in the industrial and in the services sectors.

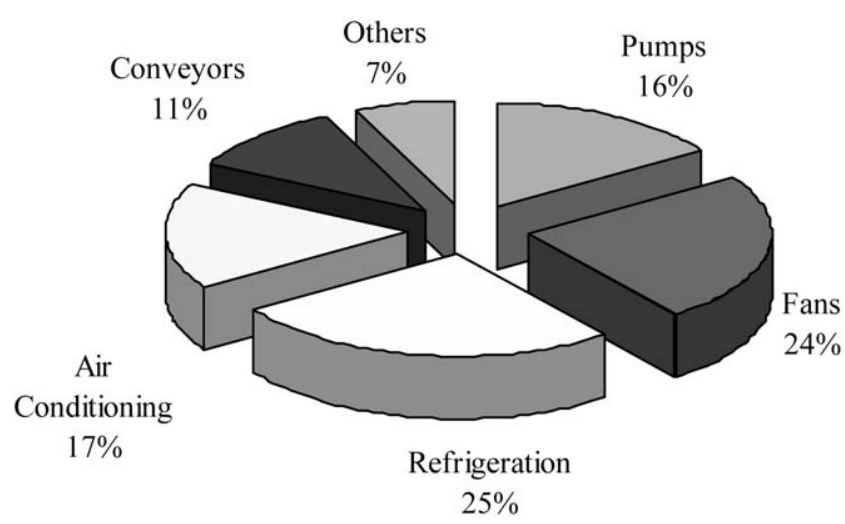

Fig. 2. Disaggregation of motor electricity consumption by end-use in the services sector. 


\section{Field characterization}

In order to understand how electricity is used by motor systems in the EU, the most significant sectors in each country have been characterized with field studies. The surveyed industrial sectors represent about three quarters of the industrial electricity consumption in Europe. Based on the sectoral characterization of each country and on the total electricity consumption by sector in the countries surveyed, the information collected in the field characterization was then extrapolated for the 15 countries of the EU.

\subsection{Data collection methodology}

There was no single process to collect the motor end-use data. The field characterisation was based on audits, on-site checks, interviews and on already existing data from field surveys. In order to standardise the information and to integrate all the data from each country, some guidelines have been established. The following guidelines helped to define what type of information should be collected in each sector.

- Distribution of the electricity consumption by types of load in the industrial and services sectors (motor load, lighting and other loads).

- Distribution of the motor electricity consumption by end-use in the industrial sector (pumps, fans, air compressors, cooling compressors, conveyors and other motors-mills, mixers, stirrers, etc.).

- Distribution of the motor electricity consumption by end-use in the services sector (pumps, fans, refrigeration, air conditioning, conveyors-lifts and escalators-and other motors).

- Kind of motors considered (AC induction motors were the focus of the characterization, because they represent more than $90 \%$ of the motor electricity consumption) [2].

- Power ranges considered $(0-0.75,>0.75-4,>4-10,>10-30,>30-70,>70-130,>130-500$, $>500) \mathrm{kW}$.

For each power range the following information was sought:

- Age and lifetime

- Number of motors in operation by power range

- Number of operating hours by power range

- Average power by power range

- Load diagrams

- Oversizing

- Variable speed requirements

- Installed capacity by power ranges

- Load factor (average load of the motor as a function of nominal power, during operating hours)

- Efficiency by power range $(\eta)$

The average EURODEEM (European Database of Energy-Efficient Motors) [5] efficiencies were confirmed through the values obtained in field checking of motor efficiency data. 
The above collected data enabled each partner to determine the motor electricity consumption in each industrial sector, by load type and by power range. The following information was prepared:

- Estimates of the electricity savings potential, through the application of Energy-Efficient Motors (EEMs), through the application of Electronic Variable Speed Drives (VSDs), and through the combined application of EEMs and VSDs for the same power ranges, in the industrial and services sectors (percentage value and GWh value), for the time horizon 2015.

\subsection{Overall assessment for the European Union}

The most important source of information was the field characterization. However, some recent statistics have been the basis for the extrapolations for the EU, namely the International Energy Agency (IEA) statistics for the year 1996 [7] (this was the most reliable data available at the beginning of the project). Another important source of information were the previous SAVE I study "Actions to Promote Energy-Efficient Electric Motors" [2], the SAVE I study "Study on Technical/Economic and Cost/Benefit Analysis of Energy-Efficiency Improvement in Industrial Three Phase Induction Motors" [6], the EURODEEM motor database [5] and the IKARUS database [7].

The countries represented in the study compose $56 \%$ of the total industrial consumption in the EU [1]. Based on individual country assessments on motor electricity use in each country and on electricity consumption statistics in the base year 1996 [8], we were able to extrapolate the data and characterize the EU situation regarding the motor electricity end-use in the industrial and services sectors. For the data extrapolations, two different situations were considered:

\subsubsection{When an industry sector was characterized by only one country}

In this case the data is extrapolated from one country to EU (Eq. 1-7):

Number of Motors $(N)$ :

$$
N_{\mathrm{EU}}=K_{\text {sector }} \times N_{\text {sample }}
$$

Installed Capacity (Cap):

$$
\operatorname{Cap}_{\mathrm{EU}}=K_{\text {sector }} \times C \text { ap }_{\text {sample }}
$$

Motor Consumption $(C)$ :

$$
\begin{aligned}
& C_{\mathrm{EU}}=K_{\text {sector }} \times C_{\text {sample }} \\
& K_{\text {sector }}=\text { Consumption }_{\mathrm{EU}} / \text { Consumption }_{\text {sample }}
\end{aligned}
$$

Operating hours $_{\mathrm{EU}}=$ Operating hours $_{\text {sample }}$

Load factor $_{\mathrm{EU}}=$ Load factor $_{\text {sample }}$

Efficiency $_{\mathrm{EU}}=$ Efficiency $_{\text {sample }}$.

\subsubsection{When there was more than one country to characterize the same industry sector}

In this case, the number of motors, the motor electricity consumption and the installed capacity were primarily aggregated by the sum of the values for each individual country and then extrapolated for EU (Eq. 8): 
Table 1

Total electricity consumption and share of motor electricity consumption in the industrial and services sectors

\begin{tabular}{lcc}
\hline Surveyed sectors & $\begin{array}{c}\text { Total electricity } \\
\text { consumption TWh [1] }\end{array}$ & $\begin{array}{l}\text { Share of motor electricity } \\
\text { consumption } \%^{\mathrm{a}}\end{array}$ \\
\hline Non-metallic mineral & 63 & 90.9 \\
Paper, pulp and print & 107 & 75.1 \\
Food, beverage and tobacco & 78 & 89.8 \\
Chemical & 165 & 71.9 \\
Machinery and metal & 98 & 51.7 \\
Iron and steel & 82 & 66.3 \\
Other industry & 242 & 59.9 \\
Total industry sector & 834 & 69.0 \\
Services sector & 520 & 38.3 \\
\hline
\end{tabular}

a The electricity consumed by motors in each sector is based on the field surveys

$$
X_{\mathrm{S}}=\Sigma X_{\mathrm{i}}
$$

Where $X_{\mathrm{s}}$ represents the values in the sample and $X_{\mathrm{i}}$ represents the values in each country.

The duty (load factor times operating hours) and motor efficiency were calculated by weighting the average values of each country by the number of motors in use (Eq. 9):

$$
X_{\mathrm{S}}=\left(\sum N_{\mathrm{i}} X_{\mathrm{i}}\right) /\left(\sum N_{\mathrm{i}}\right) \text {. }
$$

The method used to extrapolate the data for EU is similar in both situations. It has also been used to extrapolate the data in each sector, giving the relation between the EU consumption and the countries' consumptions.

Table 1 shows the total electricity consumption for the surveyed industrial sectors, and the share of electricity used by electric motors in each sector. Tables 2 and 3 show the share of motor electricity consumption by the main end-use in the industrial and services sectors, respectively.

Because the efficiency difference between standard and Energy-Efficient Motors is larger in smaller motor sizes than in large sizes, it is important to have the distribution of motors by motor size. This is most important when calculating the electricity savings potential using EEMs.

Table 2

Share of motor electricity consumption in the surveyed industrial sectors (\%)

\begin{tabular}{lrrrrrr}
\hline & Pumps & Fans & Air compressors $\begin{array}{l}\text { Cooling } \\
\text { compressors }\end{array}$ & Conveyors & $\begin{array}{l}\text { Other } \\
\text { motors }\end{array}$ \\
\hline Non-metallic mineral & 6.8 & 21.4 & 16.8 & 0.0 & 6.2 & 48.8 \\
Paper, pulp and print & 56.9 & 21.7 & 13.2 & 0.4 & 0.9 & 6.9 \\
Food, beverage and tobacco & 9.8 & 11.5 & 8.7 & 30.3 & 0.0 & 39.7 \\
Chemical & 26.4 & 10.6 & 28.1 & 5.7 & 2.6 & 26.6 \\
Machinery and metal & 8.5 & 15.0 & 14.1 & 0.0 & 5.3 & 57.1 \\
Iron and steel & 1.4 & 18.3 & 17.2 & 0.0 & 0.0 & 63.1 \\
\hline
\end{tabular}


Table 3

Share of motor electricity consumption in the services sector (\%)

\begin{tabular}{lllllll}
\hline & Pumps & Fans & Refrigeration & Air conditioning & Conveyors & Other motors \\
\hline Services & 15.8 & 24.0 & 26.1 & 16.6 & 10.9 & 6.6 \\
\hline
\end{tabular}

Table 4

Motor load characteristics by power range in the non-metallic mineral sector ${ }^{\mathrm{a}}$

\begin{tabular}{llllllll}
\hline $\begin{array}{l}\text { Output power } \\
\text { ranges, } \mathrm{kW}\end{array}$ & $\begin{array}{l}\text { Number of } \\
\text { motors }\end{array}$ & $\begin{array}{l}\text { Consumption } \\
\text { TWh/yr }\end{array}$ & $\begin{array}{l}\text { Capacity } \\
\text { GW }\end{array}$ & $\begin{array}{l}\text { Average operating } \\
\text { hours }\end{array}$ & $\eta$ & $\begin{array}{l}\text { Average } \\
\text { duty }\end{array}$ & $\begin{array}{l}\text { Average load } \\
\text { factor }\end{array}$ \\
\hline$>0 \leq 0.75$ & 314,000 & 0.6 & 0.1 & 5000 & 0.65 & 3010 & 0.60 \\
$>0.75, \leq 4$ & 584,000 & 3.3 & 0.8 & 4280 & 0.67 & 2590 & 0.61 \\
$>4, \leq 10$ & 182,000 & 3.4 & 1.2 & 4080 & 0.82 & 2370 & 0.58 \\
$>10, \leq 30$ & 108,000 & 5.2 & 1.8 & 4380 & 0.88 & 2570 & 0.59 \\
$>30, \leq 70$ & 85,200 & 11.4 & 3.5 & 4300 & 0.91 & 2930 & 0.68 \\
$>70, \leq 130$ & 32,300 & 12.7 & 2.7 & 5570 & 0.92 & 4310 & 0.77 \\
$>130, \leq 500$ & 4400 & 6.2 & 1.1 & 8590 & 0.92 & 5230 & 0.61 \\
$>500,-$ & 1990 & 14.3 & 1.9 & 8590 & 0.93 & 6870 & 0.80 \\
\hline
\end{tabular}

${ }^{\text {a }}$ Note for Tables 4-10: The 4th column represents the installed capacity of rated motor output. In the 6th column the efficiency values correspond to $3 / 4$ load. In the 7th column the average duty is the product of average operating hours and average load factor

Table 5

Motor load characteristics by power range in the paper, pulp and print sector

\begin{tabular}{llcccccc}
\hline $\begin{array}{l}\text { Output power } \\
\text { ranges, } \mathrm{kW}\end{array}$ & $\begin{array}{l}\text { Number of } \\
\text { motors }\end{array}$ & $\begin{array}{l}\text { Consumption } \\
\text { TWh/yr }\end{array}$ & $\begin{array}{l}\text { Capacity } \\
\text { GW }\end{array}$ & $\begin{array}{l}\text { Average operating } \\
\text { hours }\end{array}$ & $\eta$ & $\begin{array}{l}\text { Average } \\
\text { duty }\end{array}$ & $\begin{array}{l}\text { Average load } \\
\text { factor }\end{array}$ \\
\hline$>0, \leq 0.75$ & 49,200 & 0.1 & 0.0 & 4500 & 0.65 & 2380 & 0.53 \\
$>0.75, \leq 4$ & 317,000 & 2.6 & 0.7 & 4430 & 0.67 & 2420 & 0.55 \\
$>4, \leq 10$ & 131,000 & 3.8 & 1.1 & 6000 & 0.82 & 2950 & 0.49 \\
$>10, \leq 30$ & 176,000 & 9.7 & 2.7 & 6200 & 0.88 & 3120 & 0.50 \\
$>30, \leq 70$ & 112,000 & 16.0 & 4.2 & 6200 & 0.91 & 3480 & 0.56 \\
$>70, \leq 130$ & 44,600 & 15.0 & 4.1 & 5300 & 0.92 & 3340 & 0.63 \\
$>130, \leq 500$ & 34,600 & 26.6 & 7.2 & 5600 & 0.92 & 3390 & 0.60 \\
$>500,-$ & 2020 & 6.5 & 1.7 & 6870 & 0.93 & 3500 & 0.51 \\
\hline
\end{tabular}

Therefore, all the data has been aggregated by motor power range. Figs. 3 and 4 show the motor electricity consumption, the installed capacity and the number of operating hours by power range, in the industrial and in the services sectors in EU, respectively. 
Table 6

Motor load characteristics by power range in the food, beverage and tobacco sector

\begin{tabular}{llcccccc}
\hline $\begin{array}{l}\text { Output power } \\
\text { ranges, } \mathrm{kW}\end{array}$ & $\begin{array}{l}\text { Number of } \\
\text { motors }\end{array}$ & $\begin{array}{l}\text { Consumption } \\
\text { TWh/yr }\end{array}$ & $\begin{array}{l}\text { Capacity } \\
\mathrm{GW}\end{array}$ & $\begin{array}{l}\text { Average operating } \\
\text { hours }\end{array}$ & $\begin{array}{l}\eta \\
\text { Average } \\
\text { duty }\end{array}$ & $\begin{array}{l}\text { Average load } \\
\text { factor }\end{array}$ \\
\hline$>0, \leq 0.75$ & $2,850,000$ & 2.2 & 0.9 & 4300 & 0.67 & 1700 & 0.39 \\
$>0.75, \leq 4$ & $2,816,000$ & 11.5 & 4.2 & 4600 & 0.79 & 2140 & 0.46 \\
$>4, \leq 10$ & 816,000 & 8.6 & 4.3 & 3300 & 0.87 & 1710 & 0.52 \\
$>10, \leq 30$ & 129,000 & 6.2 & 1.8 & 5400 & 0.91 & 3150 & 0.58 \\
$>30, \leq 70$ & 95,900 & 24.1 & 4.4 & 7740 & 0.92 & 4990 & 0.65 \\
$>70, \leq 130$ & 12,000 & 3.5 & 0.9 & 5130 & 0.92 & 3580 & 0.70 \\
$>130, \leq 500$ & 19,600 & 14.1 & 3.3 & 4640 & 0.93 & 4020 & 0.87 \\
\hline
\end{tabular}

Table 7

Motor load characteristics by power range in the chemicals sector

\begin{tabular}{llllllll}
\hline $\begin{array}{l}\text { Output power } \\
\text { ranges, } \mathrm{kW}\end{array}$ & $\begin{array}{l}\text { Number of } \\
\text { motors }\end{array}$ & $\begin{array}{l}\text { Consumption } \\
\text { TWh/yr }\end{array}$ & $\begin{array}{l}\text { Capacity } \\
\text { GW }\end{array}$ & $\begin{array}{l}\text { Average operating } \\
\text { hours }\end{array}$ & $\begin{array}{l}\eta \\
\text { Average } \\
\text { duty }\end{array}$ & $\begin{array}{l}\text { Average load } \\
\text { factor }\end{array}$ \\
\hline$>0.75, \leq 4$ & $4,230,000$ & 2.0 & 0.5 & 4090 & 0.75 & 2670 & 0.66 \\
$>4, \leq 10$ & 313,000 & 6.2 & 1.6 & 4900 & 0.85 & 3280 & 0.67 \\
$>10, \leq 30$ & 125,000 & 7.1 & 1.8 & 4700 & 0.88 & 3530 & 0.75 \\
$>30, \leq 70$ & 107,000 & 14.8 & 4.2 & 5500 & 0.91 & 3220 & 0.58 \\
$>70, \leq 30$ & 37,600 & 13.7 & 3.1 & 5900 & 0.92 & 4050 & 0.69 \\
$>130, \leq 500$ & 39,500 & 35.0 & 9.1 & 6680 & 0.93 & 3540 & 0.53 \\
$>500,-$ & 8900 & 39.6 & 6.6 & 7700 & 0.94 & 5600 & 0.73 \\
\hline
\end{tabular}

Table 8

Motor load characteristics by power range in the machinery and metal sector

\begin{tabular}{lllrrrrr}
\hline $\begin{array}{l}\text { Output power } \\
\text { ranges, } \mathrm{kW}\end{array}$ & $\begin{array}{l}\text { Number of } \\
\text { motors }\end{array}$ & $\begin{array}{l}\text { Consumption } \\
\text { TWh/yr }\end{array}$ & $\begin{array}{l}\text { Capacity } \\
\mathrm{GW}\end{array}$ & $\begin{array}{l}\text { Average operating } \\
\text { hours }\end{array}$ & $\begin{array}{l}\eta \\
\begin{array}{l}\text { Average } \\
\text { duty }\end{array}\end{array}$ & $\begin{array}{l}\text { Average load } \\
\text { factor }\end{array}$ \\
\hline $0, \leq 0.75$ & $5,150,000$ & 0.9 & 1.5 & 1250 & 0.57 & 320 & 0.26 \\
$>0.75, \leq 4$ & $5,280,000$ & 6.8 & 12.1 & 1160 & 0.77 & 430 & 0.37 \\
$>4, \leq 10$ & $2,200,000$ & 8.7 & 11.4 & 1550 & 0.85 & 650 & 0.42 \\
$>10, \leq 30$ & $1,420,000$ & 25.0 & 24.2 & 1800 & 0.90 & 930 & 0.52 \\
$>30, \leq 70$ & 220,000 & 12.7 & 7.7 & 2440 & 0.92 & 1520 & 0.62 \\
\hline
\end{tabular}

\section{Major findings in each surveyed sector}

In this section we briefly present the most relevant data on motor electricity use by power range for each surveyed sector in the EU. The characterisation includes the number of motors, the electricity consumption, the installed capacity, the average number of operating hours, the average efficiency, the average duty and load factor, for the different power ranges in each surveyed sector. This information is presented in Table 4 [1]. 
Table 9

Motor load characteristics by power range in the iron and steel sector

\begin{tabular}{llcccccc}
\hline $\begin{array}{l}\text { Output power } \\
\text { ranges, } \mathrm{kW}\end{array}$ & $\begin{array}{l}\text { Number of } \\
\text { motors }\end{array}$ & $\begin{array}{l}\text { Consumption } \\
\text { TWh/yr }\end{array}$ & $\begin{array}{l}\text { Capacity } \\
\text { GW }\end{array}$ & $\begin{array}{l}\text { Average operating } \\
\text { hours }\end{array}$ & $\eta$ & $\begin{array}{l}\text { Average } \\
\text { duty }\end{array}$ & $\begin{array}{l}\text { Average load } \\
\text { factor }\end{array}$ \\
\hline$>0.75, \leq 4$ & 389,000 & 1.9 & 0.5 & 4380 & 0.75 & 2890 & 0.66 \\
$>4, \leq 10$ & 160,000 & 2.7 & 0.8 & 4160 & 0.85 & 2790 & 0.67 \\
$>10, \leq 30$ & 62,000 & 3.5 & 0.9 & 4750 & 0.88 & 3560 & 0.75 \\
$>30, \leq 70$ & 45,100 & 6.9 & 1.8 & 6100 & 0.91 & 3540 & 0.58 \\
$>70, \leq 130$ & 11,000 & 5.1 & 0.9 & 7400 & 0.92 & 5100 & 0.69 \\
$>130, \leq 500$ & 17,700 & 17.4 & 4.1 & 7450 & 0.93 & 3940 & 0.53 \\
$>500,-$ & 3020 & 13.4 & 2.3 & 7560 & 0.94 & 5520 & 0.73 \\
\hline
\end{tabular}

Table 10

Motor load characteristics by power range in the services sector

\begin{tabular}{llrrrrrr}
\hline $\begin{array}{l}\text { Output power } \\
\text { ranges, } \mathrm{kW}\end{array}$ & $\begin{array}{l}\text { Number of } \\
\text { motors }\end{array}$ & $\begin{array}{l}\text { Consumption } \\
\mathrm{TWh} / \mathrm{yr}\end{array}$ & $\begin{array}{l}\text { Capacity } \\
\mathrm{GW}\end{array}$ & $\begin{array}{l}\text { Average operating } \\
\text { hours }\end{array}$ & $\eta$ & $\begin{array}{l}\text { Average } \\
\text { duty }\end{array}$ & $\begin{array}{l}\text { Average load } \\
\text { factor }\end{array}$ \\
\hline$>0, \leq 0.75$ & $15,800,000$ & 11.7 & 6.9 & 2380 & 0.66 & 1120 & 0.47 \\
$>0.75, \leq 4$ & $31,700,000$ & 54.8 & 58.0 & 1390 & 0.79 & 750 & 0.54 \\
$>4, \leq 10$ & $10,300,000$ & 48.7 & 56.7 & 1300 & 0.85 & 730 & 0.56 \\
$>10, \leq 30$ & $3,640,000$ & 44.4 & 65.4 & 1100 & 0.88 & 600 & 0.55 \\
$>30, \leq 70$ & 303,000 & 10.5 & 10.6 & 1570 & 0.9 & 890 & 0.57 \\
$>70, \leq 130$ & 95,500 & 8.8 & 8.1 & 1650 & 0.93 & 1010 & 0.61 \\
$>130, \leq 500$ & 23,900 & 5.2 & 6.0 & 1400 & 0.95 & 830 & 0.59 \\
$>500,-$ & 4420 & 1.5 & 2.6 & 1070 & 0.96 & 550 & 0.52 \\
\hline
\end{tabular}

\subsection{Non-metallic mineral sector}

Mills, extruders, rollers and large production machinery are responsible for about half of the total motor electricity consumption in this sector, especially in the higher power ranges. Since most of the factories operate continuously, the average number of operating hours is high.

\subsection{Paper, pulp and print}

Centrifugal loads (pumps, fans and compressors) use about $92 \%$ of the motor electricity consumption in this sector. Pumps are by far the most important type of motor load, accounting for $57 \%$ of the total motor electricity consumption. The average number of operating hours is high.

\subsection{Food, beverage and tobacco}

Pumps, fans and compressors represent $60 \%$ of the motor electricity consumption, of which about half are for cooling compressors. When assessing the savings potential, the application of VSDs was only considered for variable loads of centrifugal type. Other motors include mixers, 


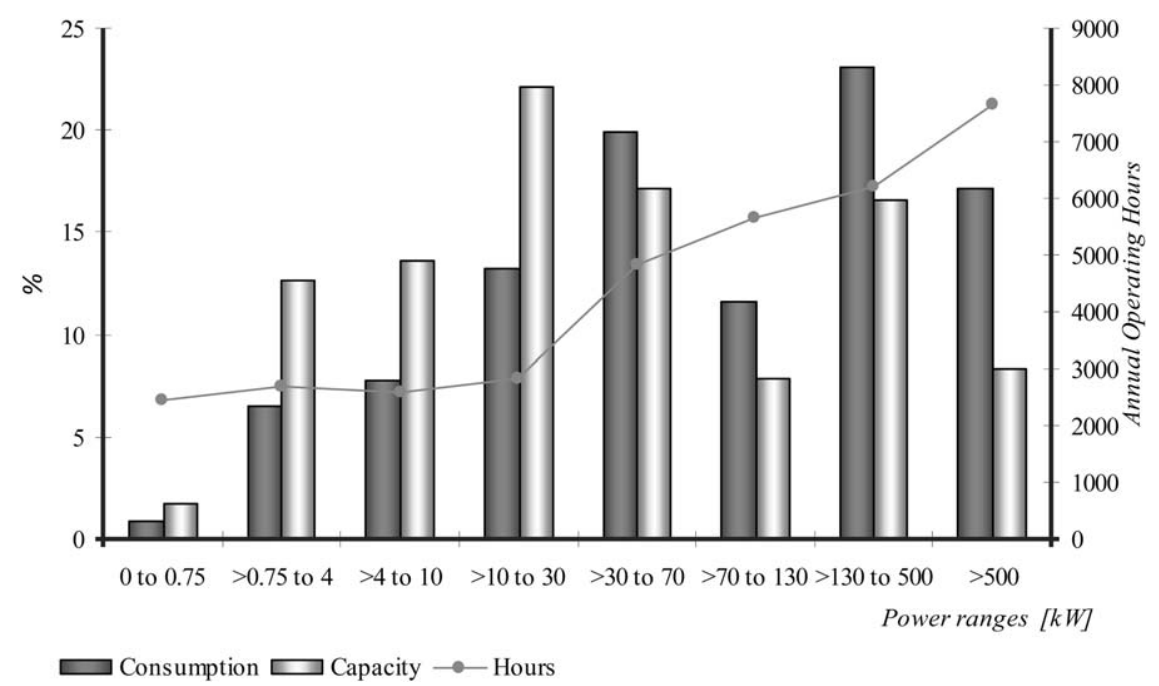

Fig. 3. Motor electricity use, installed capacity and number of annual operating hours by size range in the industrial sector.

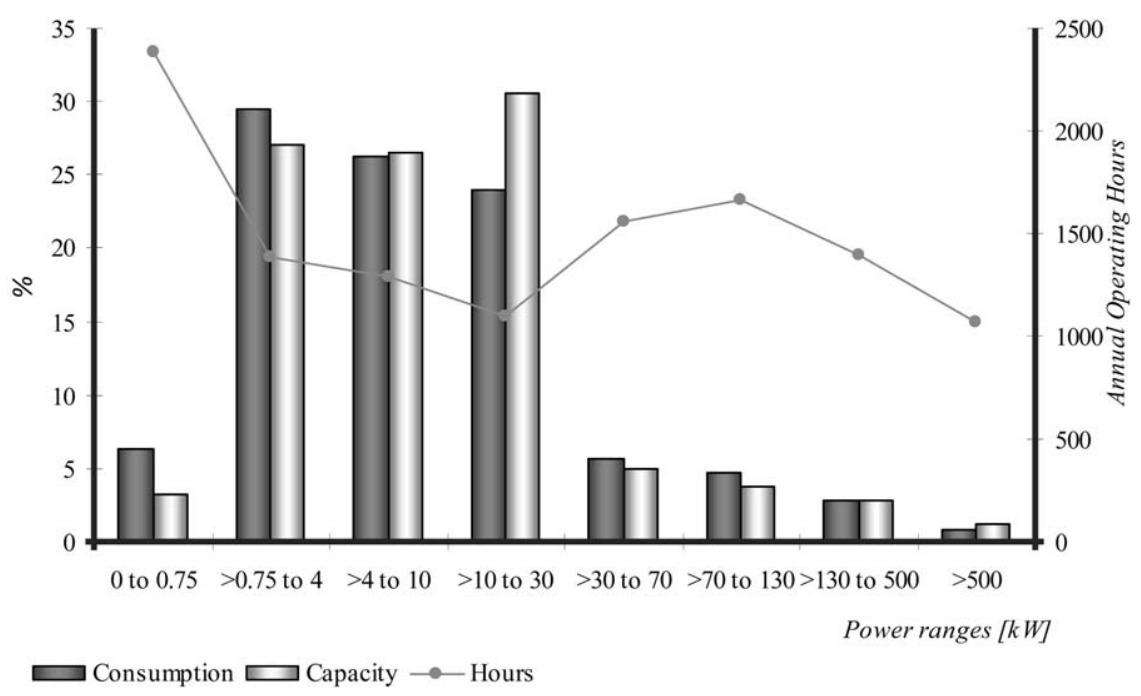

Fig. 4. Motor electricity use, installed capacity and number of annual operating hours by size range in the services sector.

conveyor belts, packaging machines and processing machines. Motors up to $4 \mathrm{~kW}$ are significantly oversized, being particularly good candidates to be replaced with smaller EEMs when they fail. They represent an attractive opportunity for electricity savings, because of the relatively larger efficiency difference between standard and EEMs for motors up to $4 \mathrm{~kW}$. 


\subsection{Chemicals}

Pumps, fans and compressors represent about $71 \%$ of the total motor electricity consumption in this sector. This high share of controllable loads is responsible for the large savings potential identified in this sector. Motors above $130 \mathrm{~kW}$ are responsible for $63 \%$ of the total motor electricity consumption. Mixers, stirrers, agitators and dispersers are common motors in chemical plants.

\subsection{Machinery and metal}

Pumps, fans and compressors only represent $37 \%$ of the total motor electricity consumption [1]. Machine tools, handling equipment, robotic systems, cranes and process machinery have the largest share of motor consumption (63\%). All motors, especially motors below $0.75 \mathrm{~kW}$ have low load factors, resulting in a significant drop in efficiency. It should be noted that the field characterization only targeted light metal industry.

\subsection{Iron and steel}

The steel sector includes two types of operation: steel making and forming. Motors related to steel forming in rolling mills, sanding, casting and finishing, account for the largest share of motor electricity consumption. In steel making pumping for cooling and fans for dust extraction are important loads in terms of electricity saving potential. Fans, which are excellent candidates for VSDs, are the second largest energy users, and are mainly used for dust and waste gas extraction and for air blowing.

\subsection{Services sector}

Pumps, fans and compressors are by far the most important loads in the services sector, accounting for $83 \%$ of the total motor electricity consumption. Most motors, especially small motors are oversized. Motors up to $30 \mathrm{~kW}$ represent about $86 \%$ of the motor electricity consumption, making them a specific target when evaluating the energy savings with EEMs.

\section{Identified potential electricity savings}

To estimate the electricity savings potential, the time horizon of 2015 has been considered. According to the "European Energy to 2020", [4], the annual average growth rates of the electricity consumption up to 2015 , in the industrial and in the services sectors, are estimated to be 1.2 and $1 \%$, respectively. Thus, motor electricity consumption by 2015 is estimated to be 721 TWh in industry and $242 \mathrm{TWh}$ in the services sector [1].

The potential electricity savings have been estimated considering two different conditions: the economic savings potential, which only consider cost-effective opportunities, and the technical savings potential, which considers the application of the efficient technologies to all the available opportunities, irrespective of the cost-effectiveness of the measure. Cost-effectiveness analysis, 
Table 11

Estimated technical savings potential in TWh by the year 2015 in industry and in the services sectors

\begin{tabular}{lrrr}
\hline & EEMs & VSDs & EEMs+VSDs \\
\hline Basic chemistry & 5.0 & 15.5 & 20.0 \\
Food, beverage and tobacco & 2.9 & 8.0 & 10.6 \\
Iron and steel & 2.3 & 6.3 & 8.4 \\
Machinery and metal & 2.1 & 6.4 & 8.3 \\
Non-metallic mineral & 3.5 & 7.4 & 10.5 \\
Paper and cardboard & 4.3 & 15.4 & 19.1 \\
Other industries & & 11.9 & 15.5 \\
Total industry in EU & 4.0 & 71.0 & 92.4 \\
Total services & 24.1 & & 34.7 \\
\hline
\end{tabular}

${ }^{a}$ Other industries include the non surveyed industrial sectors such as: non-ferrous metals, transport equipment, mining and quarrying, wood and wood products, construction, textiles and leather and other non-specified

based on the cost of saved energy showed that it is cost-effective to apply EEMs in all power ranges leading to payback times less than three years.

In what concerns VSDs there are some situations in which the introduction of variable speed controls is not attractive, especially in the lower power ranges. Tables 11 and 12 summarize the estimated technical and economic savings potential in TWh by the year 2015 in industry and in the services sectors, respectively.

Since the application of EEMs is cost-effective, their economic potential is equal to its technical potential. In Tables 13 and 14 the percentage of motors in which the application of VSDs is costeffective in each surveyed industrial sector and in the services sector can be seen, respectively. In the industrial sector, with a large number of operating hours, the fraction of application in which VSDs are cost-effective is larger than in the services sector, where the number of operating hours is significantly less. The higher cost of electricity in the services sector partially compensates

Table 12

Estimated economic savings potential in TWh by the year 2015 in industry and in the services sectors

\begin{tabular}{lrrr}
\hline & EEMs & VSDs & EEMs+VSDs \\
\hline Basic chemistry & 5.0 & 11.3 & 15.9 \\
Food, beverage and tobacco & 2.9 & 4.2 & 6.9 \\
Iron and steel & 2.3 & 4.3 & 6.5 \\
Machinery and metal & 2.1 & 1.5 & 3.6 \\
Non-metallic mineral & 3.5 & 5.0 & 8.2 \\
Paper and cardboard & 4.3 & 11.1 & 14.9 \\
Other industries & 4.0 & 7.5 & 67.3 \\
Total industry & 24.1 & 44.9 & 1.3 \\
Total services & 11.5 & 11.4 & 22.2 \\
\hline
\end{tabular}


Table 13

Percentage of motors in which the application of VSDs is cost-effective in each surveyed industrial sector

\begin{tabular}{lcccccc}
\hline & $\begin{array}{l}\text { Non-metallic } \\
\text { mineral }\end{array}$ & $\begin{array}{l}\text { Paper pulp } \\
\text { and print }\end{array}$ & $\begin{array}{l}\text { Food, beverage } \\
\text { and tobacco }\end{array}$ & $\begin{array}{l}\text { Basic } \\
\text { chemistry }\end{array}$ & $\begin{array}{l}\text { Machinery and } \\
\text { metal }\end{array}$ & $\begin{array}{l}\text { Iron and } \\
\text { steel }\end{array}$ \\
\hline Pumps & 36 & 38 & 26 & 37 & 27 & 32 \\
Fans & 39 & 35 & 34 & 40 & 28 & 38 \\
Air compressors & 19 & 18 & 15 & 19 & 13 & 18 \\
$\begin{array}{l}\text { Cooling } \\
\text { compressors }\end{array}$ & 0 & 27 & 18 & 27 & 0 & 27 \\
$\begin{array}{l}\text { Conveyors } \\
\text { Other motors }\end{array}$ & 15 & 33 & 0 & 18 & 0 & 13 \\
\hline
\end{tabular}

Table 14

Percentage of motors in which the application of VSDs is cost-effective in the services sector

$\begin{array}{lr}\text { Pumps } & 40 \\ \text { Fans } & 22 \\ \text { Refrigeration } & 20 \\ \text { Air conditioning } & 11 \\ \text { Conveyors } & 0 \\ \text { Other motors } & 0\end{array}$

the reduction in operating hours. While the savings potential available in industry is concentrated in large motors, the savings potential available in the services sector is concentrated in motors below $30 \mathrm{~kW}$, due to their relative importance in the use of electricity.

Considering the technical potential, the large-scale application of VSDs can lead to 96 TWh electricity savings, and the application of EEMs leads to 36 TWh electricity savings [1]. These electricity savings would translate into $64 \mathrm{Mton} \mathrm{CO}_{2}$ savings, contributing to the global goal of reducing greenhouse gas emissions, and thus helping to meet the goals agreed in the 1997 Kyoto Environment Conference.

\section{Barriers for energy efficiency improvements}

Despite the economic attractiveness in many cases of EEMs and VSDs, their market penetration is still relatively low. In the study the reasons for this market behavior were investigated in the field, through contacts with the users, mostly through their energy managers. Additionally contacts with consultants, equipment distributors, equipment manufacturers, and energy agencies were also carried out.

The most common barriers for the application of energy-efficient technologies identified in the field include split budgets (different capital and operations budgets), risk of failure, lack of internal incentives and market structure. A combination of educational tools, promotional activities and financial incentives, has been identified as being the most successful way to promote improved energy-efficient motor systems. 
In general, most of the barriers identified in the field characterization are common to all the surveyed sectors. Some barriers that were particularly specific in some sectors are highlighted below.

There is a high level of general awareness of the potential use of EEMs and VSDs to save energy. However, most motor users are still skeptical about the claimed amount of energy savings from different sources, which sometimes seems conflicting. On the other hand, some tools and publications are often too complicated or too basic, not matching the motor user's requirements. Barriers to the penetration of EEMs and VSDs can be separated as follows:

\subsection{EEMs}

Induction motors are their own "worst enemy", because they are reliable, quiet, will survive with little or no maintenance and have a low first cost [3]. In addition, standard designs mean that there is practically very little differentiation between different motor manufacturers, which means that it is a very cost conscious, commodity market. When selecting a motor for a particular application, factors such as availability, service and known brand name are usually more important factors than efficiency. Although first cost is often considered the most important factor, most users actually mention the other factors as being at least so important as efficiency. Moreover, the relatively small improvements in efficiency seem too low for the non-technical personnel, who usually are in charge of purchasing drive power equipment. In many cases the decision makers are untrained and uninvolved in the energy use consequences of their choices.

For the few companies who are open to the idea of paying more for improved efficiency, the absence in Europe until July 1999, of an EEM definition means that they must separately evaluate the efficiencies of motors from catalogues. This barrier may be overcome with the new agreement between the motor manufacturers' association (CEMEP) [9] and the European Commission, and the EURODEEM [5] motor database and selection software. On average, motors are repaired twice before replacement. A poor motor repair can decrease the motor efficiency by $1-4 \%$ [10]. Since it is practically impossible to measure accurately in the field the motor efficiency of an existing motor, the effect of a poor motor repair cannot readily be identified. Motor users want some confidence that an EEM really makes a difference in power consumption. The lower slip and hence higher speed of an EEM means that they will draw more power. If advantage cannot be taken from this extra work, then the system efficiency will be reduced. This is particularly a problem in applications such as driving a centrifugal fan or pump. Alternatively, the final drive speed can be adjusted by altering pulley ratios or having external speed controls. In cases where EEMs suppliers did not warn customers in advance, a simple current measurement before and after installing an EEM can cause the customer to become very dissatisfied and hence deterred from further EEM purchases.

The need for reducing downtime, which the associated costs of lost production, leads to the replacement of failed motors as quickly as possible. This means that the existing stock of old motors, and fast repair of failed motors, will continue to hinder the penetration of EEMs into the market. 


\subsection{VSDs}

Typical problems such as the generation of harmonics into the mains supply, electromagnetic interference (EMI) susceptible equipment, earlier failure of old motors due to faster voltage rates of rise in the Pulse-Width Modulation (PWM) synthesized waveforms presented in most VSD designs, unreliable earlier versions of VSDs, etc., has led to a lot of generally unwarranted concern among motor users. The high PWM frequencies may generate radiated noise and may cause significant damage to the motor by producing bearing currents and insulation voltage stress. In certain instances, harmonics can also excite resonances especially when distributed power factor correction capacitors are present. These high frequencies can produce electromagnetic interference both as high frequency airborne radiated interference mostly in the inverter to motor cable, as well as the conducted noise in the supply cables. However, low cost solutions are now available in the market to overcome these possible problems. Possible problems can be avoided by the following measures:

- Keeping the motor-VSD link as short as possible

- Proper grounding

- Proper shielding

- Passive or active harmonic filters

- Isolation transformers

- Isolated bearings

Safety concerns are a common constraint in some safety critical industries like petro-chemicals, where the danger of uncontrolled over-speed can lead to a disaster. Besides the failure of VSDs, unauthorized access could also cause major damage by altering settings on VSDs. The commissioning of earlier VSDs and their interfaces were usually too complex, and manufacturers are now offering simpler control panels. In addition to this difficulty, the costs of associated hardware such as enclosure, cabling, switchgear, etc., can significantly increase the installation costs of VSDs. The large scale production of VSDs has led their prices to significantly drop. While the reduction in price may be good, it does mean that the effort the supplier can spend in helping to find and offer system designs for likely applications is falling fast. The move by VSD suppliers to focus on service and support rather than the product is good, but it will inevitably mean, that as with personal computers, the customer must be increasingly prepared to look and pay for service and support rather than simply buying the lowest cost product.

Besides the above specific barriers for EEMs and VSDs, there are other important barriers to improving the energy efficiency of motors and drives, which deserve to be considered, namely economic barriers, internal conflicts and market structure.

\subsection{Economic barriers}

There are several reasons why energy saving projects may be rejected for economic reasons, such as insufficient running hours to make the measure cost-effective, high initial price of equipment, leading to paybacks over three years and earlier bad experiences of energy saving equipment that have not delivered the expected benefits. 


\subsection{Internal conflicts}

While individual departments of an organization will usually acknowledge that it makes sense to invest in energy efficiency, in practice there are many internal pressures and conflicts, which make implementation very difficult. Many engineers complain that their sound investment plans have been rejected by those in charge of purchasing drive power equipment (accountants or other decision makers). However, in many cases this happens because engineers are weak at putting over their case for investment, in terms with which the decision maker is familiar. Another important reason for investments not being made is split budgets and lack of internal incentives. Many firms are organized into individual departments each one having their own budget. This situation implies the partitioning costs of equipment through the different departments, but only one department will benefit from the investment. Besides, there is a lack of internal rewards for departments and/or people for reducing energy costs. This could even imply a reduced budget next year, which is an active disincentive to take action. Some energy managers very often have to take on other responsibilities such as Health and Safety or Quality Assurance which have to take priority because they are legally required.

\subsection{Market structure}

Around $80 \%$ of low voltage induction motors are sold through original equipment manufacturers (OEMs) [2,3], who do not have to pay the energy bill and because they compete largely on the basis of price, they avoid the use of more expensive Energy-Efficient Motors and VSDs. This is a very significant problem, and ultimately it is up to purchasers to stimulate availability of improved efficiency equipment by demanding it from suppliers, who otherwise have little incentive to make it available.

\section{Measures to overcome the barriers}

Experience of many energy saving initiatives around the world shows that the most effective way to transform the market towards improved energy efficiency is a combination of technical information and financial incentives [11]. The contacts with the users in the different sectors, consultants, equipment distributors, equipment manufacturers, and energy agencies provided insights on the possible strategies to overcome the barriers identified in the previous section.

\subsection{Educational/promotional needs}

Typically, the target of motor-based energy saving initiatives are technical personnel, who are usually responsible for the identification of energy saving projects. They need promotional/educational materials and schemes which will address their needs to implement successful energy saving projects. Some of these materials are: technical information on energy saving options, attendance at exhibitions, guides giving an independent assessment of the equipment available, videos, calculation aids such as software, product selectors such as the motor data base EURODEEM [5] and accreditation / labeling of products. Case studies especially real life energy 
savings stories showing both the benefits and possible problems, can provide confidence to readers and inspire others to replicate the measures. Seminars, dissemination of information both through software programs (discs, internet) and printed documents, energy saving helplines, etc., also seem to have an effect in the motor market transformation.

In order to identify which particular applications will give the most favorable investment in energy efficiency, it is important to supply motor users with educational tools (e.g. calculating aids) that are friendly to use, as well as training them about the type of measurements needed to assess the potential savings and also training in creating and presenting proposals in order to apply for funds from energy conservation programs.

\subsection{Financial measures}

Financial incentives for energy efficiency have been frequently discussed in existing literature. Therefore this paper will focus on motor specific issues [12].

Financial incentives are crucial measures to stimulate the market for energy saving products. Such incentives could be rebates, payments by savings, leasing, bidding, penalties and loans. Rebates have successfully been applied to EEMs, where they are typically set to equal the price premium of EEMs. However, rebates for VSDs are not so easy to set, since VSDs are often sold because of better process control and longer equipment lifetime reasons, rather than for energy saving reasons. Several utilities and equipment suppliers have tried schemes in which equipment (usually VSDs) is paid for from the energy savings. However, many of these schemes have failed because of the difficulty in agreeing the exact terms of agreement, which should be settled based on reasonable estimates of energy savings, which should be as close as possible to real savings, in order to avoid later disputes.

It is unlikely that motors and VSDs will be leased. However, some packaged OEM products, particularly air compressors, are commonly leased. Concerning penalties, various forms of taxes on electricity bills are effective to help improve the attractiveness of energy saving measures. A successful example of penalties is the green taxes in Denmark, in which the collected funds are used to pay for the investments in energy-efficient equipment, including EEMs and VSDs. Additionally a "guzzler tax" could be levied on less-efficient equipment.

In addition to educational programs, and financial incentives, there are some key points which need promoting such as:

- Energy saving is a key issue leading not only to economic benefits but also to positive public relations, social and environmental benefits.

- Internal finance systems should not work against energy saving campaigns.

- Reducing wear, lower maintenance costs, production or quality benefits of energy saving projects can greatly boost the likelihood of winning funding.

- Energy costs should be taken account of in procurement, (i.e. Life cycle costing).

- One or more people need to be responsible for energy saving.

- Energy must be measured and usage attributed to user areas.

- Services, such as heating, ventilation, steam, compressed air, cooling, must not be thought of as free.

- Big savings can be found by considering the whole motor system and not just the drive (motor plus VSD). 
More research and development is needed to bring to the market new energy saving products at a reduced price. Concerning EEMs, there are still important areas for further development to reduce energy losses, such as: lower loss steel, cast copper rotors, design for minimum stray loss and optimized design of motors for inverter control. In what concerns VSDs, there are two key areas which need further research and development namely lower cost power electronics and easier commissioning and setting up. VSDs price has been dropping because of the global market competitiveness. Additionally, further R\&D is also needed in order to bring to market new low cost topologies such as integrated motors with VSDs as well as permanent magnet and switched reluctance drives, which can be used for speed control in applications in which they have better performance than induction motor drives.

\section{Conclusions}

This paper has briefly characterized the motor electricity end-use in some industrial sectors in EU, namely non-metallic mineral, paper pulp and print, food beverage and tobacco, chemicals, machinery and metal, in the iron and steel sectors, and in the services sector. The surveyed industrial sectors represent $72 \%$ of the total industrial electricity consumption in EU.

Technical electricity savings potential of about 92 and $35 \mathrm{TWh}$, in the industrial and in the services sectors, respectively, have been estimated. Although there is a large identified potential for electricity savings in industry and in the services sector, EEMs and VSDs have not yet been widely applied in Europe. Among the several identified barriers associated with the use of efficient equipment, split budgets, risk of failure and lack of internal incentives could be mentioned as the most important obstacles for EEMs and VSDs. A mixture of educational tools, promotional activities and financial incentives is needed to promote such technologies in an effective way. Concerning the educational tools, it is important to ensure that they will address the differing needs of different personnel with different backgrounds. Personalized advice through telephone helplines and on site support is invaluable to improve energy efficiency but it needs considerable funds to be successful. Tools and other products alone are not sufficient and clear basic messages relating to energy saving need to be re-iterated through a wide variety of channels. Equipment suppliers and other third parties can be used in a coordinated way to "gear up" effort to promote the market transformation of energy-efficient motors and drives.

\section{References}

[1] De Almeida A, et al. Improving the penetration of energy-efficient motors and drives. Report prepared for the European Commission, SAVE II. Coimbra, ISR-University of Coimbra, Portugal, 2000.

[2] Motors Study Group. Actions to promote energy-efficient electric motors. Brussels, European Commission, DGXVII, 1996.

[3] De Almeida A, Bertoldi P, Leonhard W. Energy efficiency improvements in electric motors and drives. Berlin: Springer Verlag, 1997.

[4] European Commission. European energy to 2020. Brussels, Directorate-General for Energy (DG XVII), Spring 1996.

[5] EURODEEM-European database of energy-efficient motors, Joint Research Centre, European Commission. See also: http://iamest.jrc.it/projects/eem/eurodeem.htm. 
[6] Parasiliti F, et al. Study on technical/economic and cost/benefit analysis of energy-efficiency improvement in industrial three phase induction motors. Aquila, University of L'Aquila, Italy, 1999.

[7] FIZ Karlsruhe/Projektgruppe, Energie und Umwelt, Germany. See also www.fiz-karlsruhe.de/peu/ika2.html

[8] Electricity consumption by sector in Europe. International Energy Agency. Electricity information (1998 Edition).

[9] European Commission and European Committee of Manufacturers of Electrical Machines and Power Electronics (CEMEP), 1999. Draft agreement of CEMEP, June 1999.

[10] De Almeida A, et al. Barriers against energy-efficient motor repair. Report prepared for the European Commission, SAVE II. Coimbra, ISR-University of Coimbra, Portugal, 1999.

[11] Nadel S, Shepard M, Greenberg S, Katz G, de Almeida A. Energy-efficient motor systems, 2nd ed. Washington, D.C: American Council for an Energy-Efficient Economy, 2001.

[12] Bertoldi P, de Almeida AT, Falkner H, editors. Energy efficiency improvements in electric motors and drives. Berlin: Springer Verlag; 2000. 